Volume 1 Issue 1, March 2017: pp. 33-42. Copyright (c) 2017 HOLREV. Faculty of Law, Halu Oleo University, Kendari, Southeast Sulawesi, Indonesia. ISSN: 2548-1762 | e-ISSN: 2548-1754. Open Access at: http://ojs.uho.ac.id/index.php/holrev/

\title{
Redesain Model Kameralisme Parlemen dalam Sistem Ketatanegaraan Indonesia
}

\author{
Redesigning Cameralism Model of Parliament \\ in Constitutional System of Indonesia
}

\author{
Adnan Jamal \\ Dosen Hukum Tata Negara \\ Fakultas Hukum Universitas Halu Oleo \\ E-mail:adnanjamal77@gmail.com
}

\begin{abstract}
Constitution as grund norm as well as the supreme law of the land is reflection of the whole people will. The amendment idea of the 1945 Constitution of Republic of Indonesia, in the context, is to redesign cameralism of parliament model aiming at strengthening democracy institutions and constitutional rights of citizens only as a effort to perfect the constitution the constitution. Domination and subordination paradigm in holding and discussing the constitution amendment is one of the benchmarks assessing whether constitutional change as the basic norm becomes an area of elite political transactions only or for the ultimate purpose of constitutional amendment indeed.
\end{abstract}

Keyword: cameralism; parliament; constitution.

Abstrak: Konstitusi sebagai norma dasar dan hukum tertinggi suatu negara merupakan refleksi kehendak rakyat secara keseluruhan. Ide perubahan UndangUndang Dasar Negara Republik Indonesia Tahun 1945 dalam konteks redesain model kameralisme harus menjadi suatu gagasan yang hanya bertujuan untuk penguatan institusi demokrasi di samping hak konstitusional warga Negara sebagai bagian penyempurnaan konstitusi. Paradigma dominasi dan subordinasi pada usulan dan pembahasan perubahan Undang-Undang Dasar Negara Republik Indonesia Tahun 1945 menjadi salah satu tolok ukur apakah perubahan konstitusi sebagai norma dasar hanya menjadi area transaksi politik elit atau benar-benar untuk tujuan penyempurnaan konstitusi.

Kata kunci: kameralisme; parlemen; konstitusi. 


\section{PENDAHULUAN}

Diskursus perubahan Undang-Undang Dasar Negara Republik Indonesia Tahun 1945 (UUD NRI Tahun 1945) semakin menguat. Setidak-tidaknya tampak sejak pada 2007. Institusi Dewan Perwakilan Daerah Republik Indonesia (DPD RI) adalah salah satu pihak yang secara masif dan sistematis menggagas usulan perubahan kelima UUD NRI Tahun 1945 dengan ide pokoknya adalah penguatan DPD RI agar sejajar kedudukan dan fungsinya dengan Dewan Perwakilan Rakyat Daerah Republik Indonesia (DPR RI). Pengkajian terhadap UUD NRI Tahun 1945, antara lain diarahkan padan ide mengenai penataan sistem kameralisme yang dianut oleh UUD NRI Tahun 1945 dengan ide penguatan sistem presidensial, penguatan lembaga perwakilan, dan penguatan sistem otonomi daerah.

Selain itu, terdapat pula ide penguatan MPR sebagai lembaga negara yang mempunyai kewenangan tertinggi dalam mengubah, menetapkan, dan menafsikan UUD 1945 dan melembagakan atau 'menghidupkan' kembali Garis-Garis Besar Haluan Negara (GBHN). Tentu saja, rekomendasi ilmiah dari kalangan akademisi berkaitan dengan perubahan UUD NRI Tahun 1945 juga tidak sedikit.

Ide besar perubahan UUD NRI Tahun 1945 menunjukkan materi muatan konstitusi setelah empat kali perubahan masih banyak kekurangan terutama sebagai grund norm atau the supreme law of the land bagi sejumlah pihak. Konstitusi sebagai norma hukum, memang idealnya tingkat prediktibilitasnya atas tatanan kehidupan berbangsa dan bernegara semakin jauh ke depan yang memampukannya cita negara dapat tercapai. Satusatunya tugas hukum adalah kemampuannya memprediksi kondisi pada masa yang akan datang.

Kendatipun perubahan konstitusi (UUD) bukan hal yang sakral, namun ide perubahan UUD NRI Tahun 1945 kelima, idealnya tidak sekedar sebagai bentuk desakralisasi konstitusi untuk restrukturalisasi kekuasaan negara belaka dalam sistem politik oligarkis yang justru dapat berimplikasi pada dekonstruksi tatanan kehidupan dan kebangsaan. Oleh karena itu, setidak-tidaknya perubahan itu merupakan refleksi kehendak keseluruhan rakyat. James menegaskan:

It was recognised that, "The constitution is founded on the belief that the constitution belongs to the whole people, can draw its legitimacy only from a broad-based agreement of the whole people and must not be changed without the approval of the 
whole people".1

Paradigma dominasi dan subordinasi, baik pada tahapan usulan, maupun pada perubahan UUD mesti dihindari. Konstitusi hakikatnya sebagai cerminan kehendak rakyat secara keseluruhan. Pengalaman pergantian dan perubahan konstitusi Indonesia mulai periode UUD Tahun 1945 sampai perubahan keempat UUD NRI Tahun 1945 pada 2002 dengan segala implikasinya terhadap tatanan kehidupan kebangsaan dan kenegaraan menjadi, salah satu referensi mengukur dan mengestimasi hal ihwal "kesempurnaan dan ketidaksempurnaan" konstitusi Indonesia. Selain itu, pada pengalaman tersebut menunjukkan bagaimana suasana "kebatinan" perubahan dan pergantian konstitusi Indonesia memberi andil besar terhadap struktur dan substansi materi muatan konstitusi.

\section{ANALISIS DAN PEMBAHASAN}

\section{Hakikat Perubahan Undang-Undang Dasar}

Berdasarkan pengalaman kebanyakan negara, terdapat sejumlah argumentasi mengubah atau mengganti UUD. Argumentasi tersebut, antara lain, adalah:

1. Adanya motivasi penguatan constitutional rights atau memperkuat democratic institutions;

2. Adanya motivasi untuk menyesuaikan konstitusi dengan sistem politik yang sedang berlangsung dengan dinamikanya yang mencakup sisi ekonomi, teknologi, relasi internasional, demografi, dan perubahan tata nilai domestik dan internasional dan sebagainya;

3. Adanya motivasi untuk mengoreksi bagian-bagian konstitusi yang terbukti tidak sesuai lagi dengan perkembangan zaman kekinian dan masa datang.

Namun demikian, tidak dapat dipungkiri bahwa terdapat pula motivasi lain dibalik untuk mengubah atau mengganti konstitusi. Misalnya motivasi kepentingan/tujuan yang bersifat partisan. Bagaimanapun, konstitusi dapat dipandang juga sebagai norma hukum yang terbentuk dari 'political game'. Oleh karena itu, perubahan atau pergantian konstitusi sangat berpotensi memperlemah demokrasi, menjauhi prinsip konstitusionalisme, memarginalkan minoritas, membatasi hak-hak sipil dan politik warga Negara dan lain-lain.

Perubahan/pergantian konstitusi diniscayakan didahului adanya motivasi tidak untuk demi kepentingan pragmatis, partisan, hegemonik dan berdimensi jangka pendek.

1 James C (2000) Appendix I: the conference objective. In: James C (ed) Building the constitution. Institute of Policy Studies, Wellington, h. 439 
Kepentingan bangsa dan negara harus dibaca dan diterjemahkan secara terukur dan harus merupakan hasil kontemplasi yang komprehensif serta disyaratkan terdapat pemahaman yang kuat dan utuh terhadap substansi konstitusi. Konstitusi, menurut, Hiskes merupakan wadah bagi kelompok sosial menegakkan dan memapankan nilai-nilai untuk mengawal wacana politik dan sosial bagi generasi mendatang sekaligus menjadi area memproteksi nilai-nilai tersebut dengan menginkorporasinya dalam wujud seperangkat hak dan kewajiban. Hal ini teridentifikasi pada substansi pemikiran Hiskes bahwa:

"Constitutions are where societies establish the values that are to guide political and social discourse for generations to come, and also where those values are protected by incorporating them as constitutional obligations or rights." 2

Argumentasi penguatan hak konstitusional, idealnya dijadikan argumentasi utama mendesain institusi demokrasi. Tidak sekedar terjebak pada mainstream relasi politik antar-organ negara an sich. Apalagi, substansiasi nilai-nilai ideologi tertentu dalam proses konstitusionalisasi, dekonstitusionalisasi dan rekonstitusionalisasi dalam kehidupan politik dan hukum suatu negara sulit dihindari. Oleh karena itu, perubahan UUD NRI Tahun 1945 harus benar-benar terkawal sehingga tidak menyimpangi tujuannya, yaitu penyempurnaan UUD NRI Tahun 1945.

Konstitusi tidak dapat lagi dipersepsi atau dititikberatkan pada aspek institusional dan proseduralnya secara hukum dan politik an sich, misalnya relasi antar-organ negara dan berbagai kutub kekuasaan dalam lingkup pembagian kekuasaan, tetapi yang jauh lebih esensial adalah nilai-nilai filosofi apa yang mendominasi konstitusi baik dalam pengertian formal maupun materil terutama dalam konteks hak asasi manusia yang merupakan elemen dasar konstitusi. Konstitusi menjadi refleksi arus utama ideologi tertentu dalam kehidupan sosial dan kenegaraan termasuk ideologi hak asasi manusia. Pada posisi ini, konstitusi diniscayakan menjadi penyeimbang terhadap arus utama ideologi tersebut.

\section{Mencari Format Ideal Kameralisme Parlemen dalam Sistem Ketatanegaraan Indonesia}

Dalam demokrasi modern, terdapat tiga cabang kekuasaan utama (primary state's organs) merujuk pada konsep separations of power, yaitu legislature, executive and judiciary, yang dialokasikan pada fungsi law making, execution and review.

2 R.P. Hiskes. 2009. The Human Right to a Green Future: Environmental Rights and Intergenerational Justice. (Cambridge University Press: Cambridge), hlm. 130. 
Kekuasaan Legislatif (the Legislature), pada umumnya terdiri dari representasi mayoritas rakyat dan didefinisikan sebagai majelis permusyawaratan yang diberikan fungsi pembentukan undang-undang (to pass, amend, and repeal laws). Lembaga kekuasaan ini, pada umumnya disebut parliament atau congress atau istilah lain, misalnya 'state council' sebagaimana digunakan di Sri Lanka.

Pada umumnya, parlemen (sistem kameralisme pada parlemen) dapat terdiri atas kamar atau majelis, dan biasanya berbentuk unikameral (A legislature with only one house) atau bicameral ( $A$ legislature with two houses). Namun demikian, terdapat pula beberapa model atau sistem parlemen, yaitu trikameral (tiga kamar) dan tentrakameral (empat kamar), Mengenai pilihan model ini tergantung pada konteks sejarah politik ketatanegaraan masing-masing Negara dan, tentu saja, terdapat filosofi yang mendasari pilihan tersebut.

Fungsi dan Kekuasaan Legislatif adalah:

1. Enact laws (powers to pass, amend and repeal laws)

2. Represent the people in the law-making process

3. Adopt the budget and other monetary bills

4. Checks on the judiciary and the executive

5. Amend the constitution

Dalam konteks redesain kameralisme dalam sistem ketatanegaraan Indonesia, terdapat banyak usulan pilihan model. Namun, pada ruang ini, saya hanya akan menitikberatkan pada kritik terhadap usulan pilihan model bikameralisme. Secara teoretis, pilihan terhadap model ini, setidak-tidaknya karena didasarkan pada argumentasi:

1. Ability to subdue the majoritarian dictatorship in the unicameral system, within a multi-ethnic society

2. Capacity to review the hasty legislatures brought up by the House of Representatives

3. Provides space for minority communities that are not sufficiently represented in the House of Representatives, to engage in the law-making process.

4. Engage with the professionals and experts from the different sectors .

5. Ability to 'check and balance' the powers of other elements of the government ${ }^{3}$

3 OTI Research,The Introduction To Bicameral System, May 2011.HIm.12 
Argumentasi pilihan model selain unikameralisme, seperti bikameralisme, pada prinsipnya dan idealnya hanya untuk penguatan institusi demokrasi dan hak konstitusional warga negara, khususnya untuk mencegah kekuasaan monopolistik atau hegemonik dan terbukanya ruang bagi penguatan hak konstitusional warga Negara berdasarkan prinsip demokrasi substansial, prinsip konstitusionalisme, dan prinsip keadilan. Oleh karena itu, agenda redesain kameralisme membutuhkan rincian fungsi, arah dan tujuan yang secara konstitusional jelas dan tegas agar tidak menyimpangi prinsip dasar demokrasi substansial, prinsip konstitusionalisme, dan prinsip keadilan.

Bikameralisme yang mengacu pada teori klasik Aristoteles dan Polybius, pada prinsipnya menegaskan bahwa pemerintahan yang baik adalah gabungan antara prinsip demokrasi dan oligarkhi. ${ }^{4}$ Secara historis, kebanyakan parlemen modern menerapkan sistem dua kamar. ${ }^{5}$ Model kameralisme dapat diacu,misalnya, pada model yang dikonstruksi Giovanni Sartori dengan membagi lembaga perwakilan rakyat bikameral menjadi tiga jenis, yaitu:

(1) sistem bikameral yang lemah (asymmetric bicameralism atau weak bicameralism atau soft bicameralism), yaitu apabila kekuatan salah satu kamar jauh lebih dominan atas kamar lainnya;

(2) sistem bikameral yang kuat (symmetric bicameralism atau strong bicameralism), yaitu jika kekuatan kedua dua kamar sama kuat;

(3) perfect bicameralism yaitu apabila kekuatan antara kedua kamar betul-betul seimbang. 6

Gagasan terhadap redesain model kameralisme lembaga kekuasaan dan fungsi legislatif agar tidak seperti model yang dianut UUD NRI Tahun 1945 dengan memilih symmetric bicameralism atau strong bicameralism yang mana kekuasaan kamar DPD sama kuat dengan DPR diniscayakan pengkajian yang komprehensif atas hal ini agar tidak sekedar terkanalisasi pada simplifikasi pada arus pemikiran bahwa fungsi keduanya (DPD dan DPR) harus sama kuat. Karena hakikat pilihan model ini, setidak-tidaknya diniscayakan didasarkan pada prinsip demokrasi, konstitusionalisme, prinsip keadilan

4 Robert L. Maddex, 1996, The Illustrated Dictionary of Constitutional Concepts, (Congressional Quarterly Inc., Washington), hlm. 28.

5 Allen R. Ball \& B. Guy Peters, 2000, Modern Politics and Government, edisi ke-6, (Macmillan Press Ltd.), Hlml. 190.

6 Giovanni Sartori, 1997, Comparative Constitutional Engineering: An Inquiry into Structures, Incentives and Outcomes, New York University Press, hal. 184. 
dan relevan dengan kedudukan Majelis Permusyawaratan Rakyat (MPR) sebagai joint session .

Terdapat beberapa pertanyaan yang dapat diajukan pada pilihan model ini. Antara lain adalah:

1. Bagaimana dapat dipastikan bahwa pilihan symmetric bicameralism atau strong bicameralism pemajuan hak konstitusional dapat terwujud dengan terukur menurut prinsip rule of law?

2. Bagaimana dapat dipastikan bahwa pilihan symmetric bicameralism atau strong bicameralism prinsip konstitusionalisme dan mekanisme cheks and balances dapat terwujud dengan terukur menurut prinsip rule of law?

3. Bagaimana dapat dipastikan bahwa pilihan symmetric bicameralism atau strong bicameralism yang mana penyelenggaraan fungsi legislasi, pengawasan dan anggaran tidak berpotensi terjadinya abuse of power baik secara institusional maupun secara individual (anggota) secara terukur menurut prinsip rule of law?

4. Bagaimana dapat dipastikan bahwa pilihan symmetric bicameralism atau strong bicameralism dari segi komposisi dan sistem pemilihan DPR dan DPD tidak berpotensi menghasilkan keanggotaan parlemen untuk melakukan abuse of power dalam menjalankan fungsi legislasi, pengawasan dan anggaran secara terukur menurut prinsip rule of law?

Sejumlah pertanyaan di atas menjadi salah satu kunci terukurnya mendesain sistem ketatanegaraan Indonesia, khususnya adalah hal pilihan model kameralisme. Substansinya bukan hanya terletak pada pemberian otoritas kepada institusi legislatif, tetapi pada aspek akuntabilitasnya berdasarkan prinsip rule of law. Otoritas dan akuntabilitas dalam konteks ini terutama dari dilihat dari segi relasi antara wakil rakyat dan yang diwakilinya menurut teori perwakilan (representation).

Hanna F. Pitkin ${ }^{7}$ membedakan representasi dalam empat kategori; representasi formal (formalistic representation), representasi substantif (substantive representation), representasi deskriptif (descriptive representation), dan representasi simbolik (symbolic representation). Representasi formal dipahami sebagai perwakilan politik yang berlangsung di dalam lembaga-lembaga perwakilan formal (seperti parlemen).

7 Hanna F. Pitkin, The Concept of Representation, (California Universitiy Press,Los Angeles) 
Representasi substantif dipahami sebagai model representasi di mana seorang wakil bertindak untuk (acts for) mereka yang diwakili. Sedangkan representasi deskriptif dipahami sebagai bentuk representasi di mana seorang wakil berdiri untuk (stands for) orang-orang yang secara objektif serupa. Jika wakil berdiri untuk (stands for) mereka yang diwakili namun dalam pengertian kesamaan identitas dan kebudayaan, maka ini adalah representasi simbolik. Pada sisi lain, DPR, sesungguhnya, sebagai representation of ideas (keterwakilan dalam gagasan) yang anggota atau unsurnya berasal dari partai politik. Sedangkan, DPD, sesungguhnya, sebagai representation of precence (keterwakilan dalam kehadiran) yang anggota atau unsurnya mewakili daerah provinsi.

Namun demikian, representasi politik idealnya, sekali lagi, substansinya terletak pada sisi akuntabilitas yang menyertai sisi otoritas. Apa pun pilihan mengenai distribusi kekuasaan dalam konteks kameralisme, jika sisi akuntabilitas tidak terdesain di bawah prinsip rule of law, maka dapat dipastikan bahwa potensi abuse of power sangat terbuka lebar oleh mereka yang memegang kekuasaan dan dimensi representasi politik menjauh dari substansinya. Misalnya, hal yang menjadi substansi mempertegas keanggotaan DPD dalam UUD NRI Tahun 1945 tidak boleh berasal dari partai politik, baik sebagai anggota atau pengurus.

Oleh karena itu, redesain model kameralisme parlemen tidak cukup sekedar berkonsentrasi pada sisi struktur ketatanegaraan hubungan antar-organ negara, tetapi penekannya pada pencapaian hakikat konstitusi. Konstitusi tidak dapat lagi, aksentuasinya pada aspek institusional dan proseduralnya secara hukum dan politik an sich, misalnya relasi antar-organ negara dan berbagai kutub kekuasaan dalam lingkup pembagian kekuasaan, tetapi yang jauh lebih esensial adalah nilai-nilai filosofi apa yang mendominasi konstitusi baik dalam pengertian formal maupun materil terutama dalam konteks hak asasi manusia yang merupakan elemen dasar konstitusi. Konstitusi menjadi refleksi arus utama ideologi tertentu dalam kehidupan sosial dan kenegaraan termasuk ideologi hak asasi manusia. Pada posisi ini, konstitusi diniscayakan menjadi penyeimbang terhadap arus utama ideologi tersebut.

Relevan dengan hal ini, Gunther Teubner menilai bahwa pada perspektif pandangan sistemik, peran historis konstitusi, khususnya dalam hal fundamental rights, tidak berakhir pada normatifikasi organisasi negara dan hak hukum individual, tetapi pada penjaminan kebinekaan diferensiasi sosial melawan luapan berbagai tendensi. Konstitusi muncul sebagai penyeimbang terhadap kedaruratan kondisi otonom dari 
tindakan tipikal masyarakat modern. Ha ini diketahui dari pernyataan Gunther Teubner, misalnya, bahwa:

"From a systemic viewpoint, the historical role of the constitution is not, especially when it comes to fundamental rights, exhausted in norming state organisation and individual legal rights, but consists primarily in guaranteeing the multiplicity of social differentiation against swamping tendencies. Considered historically, constitutions emerge as a counterpart to the emergence of autonomous spheres of action typical for modern societies." 8

Posisi konstitusi dalam konteks ini menjadi semakin vital dan strategis pada zaman globalisasi, seperti sekarang ini. Era globalisasi sebagai suatu zaman yang ditandai dengan ragam kompleksitas fenomena yang multidimensional seperti yang digambarkan Held bahwa:

"Globalization is a "multidimensional phenomenon involving diverse domains of activity and interaction including the economic, political, technological, military, legal, cultural, and environmental. Each of these spheres involves different patterns of relations and activity."

Sedangkan, David Harvey menilai globalisasi sebagai jubah baru kapitalisme menurut perspektif Marxis sebagaimana ia gambarkan berikut:

"from a Marxist perspective, that globalization is part of the "flexible accumulation" which is a new form of capitalism characterized by post-Fordist production and social relations. According to Harvey, the state is now in a problematic position whereby it is forced to both regulate the activities of corporate capital in the national interest on the one hand, and attract them by creating a "good business climate" on the other. This results in the empowerment of finance capital at the expense of the nation-state and organized labor. He also emphasizes the spatial re-organization of urban settings all over the world in the 1980s by the forces of the advanced capitalism as a primary (material) "condition of postmodernity." 9

Deskripsi di atas menunjukkan bahwa konstitusi tidak boleh hanya diukur secara terbatas dari perspektif yang sempit untuk jangka pendek tetapi harus dilihat pula dari berbagai sisi agar pilihan redesain ketatanegaraan Indonesia tidak justru malah menjauhi hakikatnya. Oleh karena itu, dalam konteks agenda perubahan UUD NRI Tahun 1945, tentu mensyaratkan ini pula. Banyak studi hukum ketatanegaraan menyoal materi muatan UUD NRI Tahun 1945 dari berbagai perspektif untuk sejumlah hal dapat menjadi referensi menemukan soal kelemahan atau kekurangan UUD NRI Tahun 1945 sebagai salah satu

8 Gunther Teubner, Societal Constitutionalism: Alternatives to State-centred Constitutional Theory. Storrs Lectures 2003/2004 Yale Law School. hlm.8

9 Harvey, D. The Condition of Postmodernity. (Oxford: Blackwell,1989), hlm.170. 
acuan teoretis sebelum menentukan pilihan model kameralisme parlemen yang pada hakikatnya hanya untuk penguatan institusi demokrasi dan hak konstitusional warga negara dalam konteks relasi antar-organ negara.

\section{KESIMPULAN}

Redesain kameralisme, pada hakikatnya untuk tujuan penguatan demokrasi substansial, prinsip konstitusionalisme dan hak konstitusional warga negara. Redesain tersebut diniscayakan tidak overlapping dengan sistem pemerintahan, sistem perpolitikan, bentuk negara, relasi fungsional dengan lembaga negara lainnya. Jika hanya diarahkan sekedar memperkuat kedudukan dan fungsi DPD RI tidak seperti format UUD NRI Tahun 1945 dengan memberikan kedudukan dan fungsi yang persis sama dengan DPR RI, maka ide redesain tersebut hanyalah sekedar redistribusi kekuasaan yang potensial memunculkan bentuk oligopoli baru antar-relasi kekuasaan legislatif yang berimplikasi pada cabang kekuasaan lainnya.

\section{Daftar Pustaka}

Ball, Allen R. \& B. Guy Peters, Modern Politics and Government, London: Macmillan Press Ltd. 2000.

C, James, Appendix I: the conference objective. In: James C (ed) Building the constitution. Institute of Policy Studies, Wellington 2000.

D, Harvey, The Condition of Postmodernity. Oxford: Blackwell 1989.

Hiskes, R. P., The Human Right to a Green Future: Environmental Rights and Intergenerational Justice, Cambridge: Cambridge University Press 2009.

Maddex, Robert L., The Illustrated Dictionary of Constitutional Concepts, Washington: Congressional Quarterly Inc. 1996.

OTI Research, The Introduction To Bicameral System, May 2011

Pitkin, Hanna F., The Concept of Representation, Los Angeles: California Universitiy Press 2000.

Sartori, Giovanni, Comparative Constitutional Engineering: An Inquiry into Structures, Incentives and Outcomes. New York: New York University Press 1997.

Teubner, Gunther, Societal Constitutionalism: Alternatives to State-centred Constitutional Theory, Connecticut: Storrs Lectures Yale Law School 2003/2004 